P. Fazekas, E. Bódis, A. M. Keszler, Zs. Czégény, Sz. Klébert, Z. Károly, J. Szépvölgyi: Decomposition of Chlorobenzene by Thermal Plasma Processing. Plasma Chemistry and Plasma Processing, 33(4): 765-778 (2013).

DOI: $10.1007 / \mathrm{s} 11090-013-9459-3$

The final publication is available at:

http://link.springer.com/content/pdf/10.1007\%2Fs11090-013-9459-3.pdf 


\title{
Decomposition of chlorobenzene by thermal plasma processing
}

\author{
P. Fazekas ${ }^{\text {a* }}$, E. Bódis ${ }^{\text {a }}$, A. M. Keszler ${ }^{\text {a }}$ Zs. Czégény ${ }^{a}$, Sz. Klébert ${ }^{a}$, Z. Károly a , J. \\ Szépvölgyi a,b \\ a Institute of Materials and Environmental Chemistry, Research Centre for Natural \\ Sciences, Hungarian Academy of Sciences, Pusztaszeri Street 59-68. Budapest, Hungary \\ 1025 \\ ${ }^{b}$ Research Institute of Chemical and Process Engineering, University of Pannonia, \\ Egyetem Street 10. P.O. BOX 10, Veszprém, Hungary 8200 \\ * Corresponding author: \\ E-mail address: fazekas.peter@ttk.mta.hu \\ Fax number: +36-1-438-1147 \\ Phone number: +36-1-438-1100/486
}

\begin{abstract}
Decomposition of chlorobenzene as a model molecule of aromatic chlorinated compounds was studied in radiofrequency (RF) thermal plasma both in neutral and oxidative conditions. Optical emission spectroscopy (OES) was applied for the evaluation of the plasma excitation and molecular rotational-vibrational temperature. Atomic $(\mathrm{C}, \mathrm{H}$, $\mathrm{O})$ and molecular $\left(\mathrm{CH}, \mathrm{OH}, \mathrm{C}_{2}\right)$ radicals were identified, while the morphology of the formed soot was characterized by electron microscopy. Organic compounds adsorbed on the surface of the soot after plasma processing were comprised of various polycyclic aromatic hydrocarbons (PAH) and chlorinated PAH molecules. Their amount was greatly affected by experimental conditions, especially the oxygen content and plate power. The higher input power reduced the ring number of the PAH molecules. Addition of oxygen significantly reduced the amount of both PAHs chlorinated PAH molecules but enhanced the formation of polychlorinated benzene compounds.
\end{abstract}

\section{Keywords}

Chlorobenzene, Decomposition, RF Thermal Plasma, Optical Emission Spectroscopy, Gas Chromatography Mass Spectrometry 


\section{Introduction}

Halogenated hydrocarbons used to be commonly used industrial solvents because of their advantageous properties like easy production and low flammability. However, they contribute to huge environmental problems like global warming and stratospheric ozone depletion. Furthermore, several chlorinated compounds are registered as toxic and/or carcinogenic materials. Having these facts realized in the last decades, international treaties either banned the application of several of them or made possible the disposal only in special hazardous waste deposition sites. In the absence of reliable destruction technology even now large quantities are still stored in many countries.

The chemical behaviour of chlorinated aromatic hydrocarbons could be investigated through the example of the simplest of such compounds, the chlorobenzene $\left(\mathrm{C}_{6} \mathrm{H}_{5} \mathrm{Cl}\right)$. It was used for dielectric material, heat exchanger, solvent in the dye industry and even as insecticide at the tropics. During the synthesis of phenol and DDT it acted as intermedier. Due to its widespread application high indoor concentrations of up to $72.2 \mu \mathrm{g} \cdot \mathrm{m}^{-3}$ was measured in the air in various cities of the USA [1]. This value was even higher at industrial sites in different countries (between $18.7 \mathrm{mg} \cdot \mathrm{m}^{-3}$ and $488 \mathrm{mg} \cdot \mathrm{m}^{-3}$ ) [2]. Its decomposition in the atmosphere takes place by reaction with hydroxyl radicals and photolysis. The latter is a pretty slow process, the half-life of which for chlorobenzene is one month. In natural waters the biological degradation rate is even slower: 150 days [3]. As a result, high contamination of many streams [4] was reported. Chlorobenzene was generally proved to have harmful influence on the growth, development and reproduction of the wildlife in the rivers [5-6]. Due to its lipophilic nature chlorobenzene tends to accumulate in the food chains and in the case of mammals it concentrates in the breast milk. The thermal destruction of this toxic compound via conventional high temperature decomposition processes such as pyrolysis or cracking results in toxic by-products, which are stable and also have adverse effects both on human health and on the environment, as well [7]. Considering the special characteristics of thermal plasmas such us extremely high temperatures $(\mathrm{T} \geq 9000 \mathrm{~K})$, high quench rates $\left(\sim 10^{6} \mathrm{~s} \cdot \mathrm{K}^{-1}\right)$, strong $\mathrm{UV}$ radiation, high number of reactive molecules, ions, etc. [8] the decomposition in thermal plasmas offers a safe and environmentally benign solution. 
In this paper we report on the decomposition of chlorobenzene as a model compound of the chlorinated aromatic hydrocarbons in an inductively coupled radiofrequency thermal plasma reactor both in neutral and oxidative conditions. We investigated both the obtained compounds after decomposition and the generated chemical species and fragments in the plasma as well. For this purpose the plasma column was monitored and analysed by optical emission spectroscopy.

OES is a convenient method for monitoring plasmas because chemical species can be identified and various parameters such as temperatures can be determined without any influences on the plasma state. The optical emission measurements of the Swan system of $\mathrm{C}_{2}\left(\mathrm{~d}^{3} \Pi_{\mathrm{g}}-\mathrm{a}^{3} \Pi_{\mathrm{u}}\right)$ transition are commonly used as a diagnostic tool for carbon plasmas [9-11].

\section{Experimental}

The experimental set-up consisted of an RF inductively coupled plasma torch (TEKNA PL 35) connected to a high frequency (4-5 MHz) LEPEL generator, a reactor, a cyclone, a filter unit and a vacuum pump. The chlorobenzene (Sigma Aldrich, 99\%) was delivered by peristaltic pump (Masterflex) to the atomizer probe (2.16 $\mathrm{mm}$ inner diameter) placed in the plasma. Ar flow of $9.4 \mathrm{dm}^{3} \cdot \mathrm{min}^{-1}$ was used for atomization. The plasma torch was also operated with Ar central gas and Ar sheath gas with flow rates of $15.5 \mathrm{dm}^{3} \cdot \mathrm{min}^{-1}$ and $40 \mathrm{dm}^{3} \cdot \mathrm{min}^{-1}$, respectively. In certain runs $\mathrm{O}_{2}$ was also added into the sheath gas with varying concentrations. The reactor, schematically presented on Fig. 1, was made of stainless steel with the inner diameter of $19.7 \mathrm{~cm}$ and length of $121.6 \mathrm{~cm}$. To determine the optimal conditions of $\mathrm{C}_{6} \mathrm{H}_{5} \mathrm{Cl}$ degradation process, three different plasma parameters were changed in particular tests: 1) feeding rate of $\left.\mathrm{C}_{6} \mathrm{H}_{5} \mathrm{Cl}\left(150-350 \mathrm{~g} \cdot \mathrm{h}^{-1}\right), 2\right)$ oxygen concentration $(0-10$ volume $\%), 3)$ plate power $(15-25 \mathrm{~kW})$. Using this parameters as variables we created a three-level fractional factorial design of experiments by means of Statistica 10.0 software (StatSoft Inc.) to limit the number of tests and that of samples to be characterized,. Fig. 2. shows the graphical representation of the nine experimental settings in the factorial space, while in Table 1 test conditions are listed.

Plasma emission was analysed at two spots, 70 and $180 \mathrm{~mm}$ far from the bottom of the 
plasma torch, respectively, perpendicularly to the axis of the plasma column through a quartz window. The wavelength was selected by a $55 \mathrm{~cm}$ focal length monochromator (TRIAX 550 Jobin-Yvon) having 1200 grooves $/ \mathrm{mm}$ grating. Light was collected and transferred to the entrance slit by a multi-legged fiber optics. Plasma emission was detected by an optical multi-channel analyser (CCD-3000). The spectral range and resolution was of 200-1000 $\mathrm{nm}$ and $0.2 \mathrm{~nm}$, respectively.

The solid soot was recovered from the wall of the plasma reactor. Soot particle morphology was characterized by scanning electron microscopy (SEM, ZEISS EVO 40XVP) and transmission electron microscopy (TEM, Morgagni 268D). Organic compounds adsorbed on soot after plasma treatment was ultrasonically extracted by toluene. Analysis of the extracted samples was performed by GC/MS (Agilent Techn. Inc. $6890 \mathrm{GC} / 5973 \mathrm{MSD})$ using Agilent DB-1701 capillary column $(30 \mathrm{~m} \times 0.25 \mathrm{~mm}$ i.d., $0.25 \mu \mathrm{m}$ film thickness). $1 \mu \mathrm{l}$ sample was injected to the column in splitless injection mode. The GC injector was kept at $300{ }^{\circ} \mathrm{C}$. The $\mathrm{GC}$ oven was hold at $50{ }^{\circ} \mathrm{C}$ for $1 \mathrm{~min}$, then increased to $280{ }^{\circ} \mathrm{C}$ at a rate of $10{ }^{\circ} \mathrm{C} \cdot \mathrm{min}^{-1}$. The mass spectrometer was operated at $70 \mathrm{eV}$ in the EI mode. The mass detection ranged from 14 to $500 \mathrm{Da}$.

\section{Thermodynamic calculations}

In order to estimate degradation processes thermodynamic calculations were performed in the range of $500-7000 \mathrm{~K}$ using code FACTSAGE ${ }^{\circledR}$, which is based on the minimization of Gibbs free enthalpy. Ideal gas conditions can be reasonably assumed because of the near atmospheric pressure and high temperature conditions found in this type of plasma [12]. The calculations were performed for three different conditions, as follows: neutral $\mathrm{C}_{6} \mathrm{H}_{5} \mathrm{Cl}+\mathrm{Ar}$, oxygen deficient $\mathrm{C}_{6} \mathrm{H}_{5} \mathrm{Cl}+4 \mathrm{O}_{2}+\mathrm{Ar}$ and oxidative $\mathrm{C}_{6} \mathrm{H}_{5} \mathrm{Cl}+14 \mathrm{O}_{2}+\mathrm{Ar}$. In $\mathrm{C}_{6} \mathrm{H}_{5} \mathrm{Cl}+\mathrm{Ar}$ system the main products of degradation are various atoms, ions of $\mathrm{C}, \mathrm{C}^{+}$, $\mathrm{Cl}, \mathrm{Cl}^{-}, \mathrm{Ar}^{+}, \mathrm{H}$ and small carbon clusters such as $\mathrm{C}_{2}, \mathrm{C}_{3}$. Many species of hydrocarbons appear in gas phase such as $\mathrm{CH}_{4}, \mathrm{C}_{2} \mathrm{H}_{2}, \mathrm{C}_{2} \mathrm{H}_{4}, \mathrm{C}_{4} \mathrm{H}_{2}$ molecules and $\mathrm{CH}, \mathrm{CH}_{2}, \mathrm{C}_{2} \mathrm{H}, \mathrm{C}_{2} \mathrm{H}_{3}$ reactive intermediates. The majority of these species have the maximum molar concentration at temperatures of $2500-4000 \mathrm{~K}$. The chlorine is present mainly in the form of $\mathrm{HCl}$ (Fig. 3.). 
In the presence of oxygen soot formation decreased. Molar concentration of $\mathrm{C}$ and $\mathrm{C}_{2}$ species are lower than in the case of neutral conditions in the whole temperature range. The main carbon-containing products are $\mathrm{CO}$ and $\mathrm{CO}_{2}$. Due to the introduction of oxygen, oxygen-containing species such as $\mathrm{H}_{2} \mathrm{O}, \mathrm{OH}, \mathrm{C}_{2} \mathrm{O}, \mathrm{HCO}, \mathrm{HOO}, \mathrm{ClO}$ and $\mathrm{HOCl}$ appear in high temperature plasma according to calculations. At still higher oxygen doses $\left(\mathrm{C}_{6} \mathrm{H}_{5} \mathrm{Cl}+14 \mathrm{O}_{2}+\mathrm{Ar}\right.$ system) $\mathrm{CH}_{4}$ is not formed (Fig. 4.).

During decomposition of chlorobenzene the formed small hydrocarbon molecules and radicals $\left(\mathrm{C}_{4} \mathrm{H}_{2}, \mathrm{CH}, \mathrm{CH}_{2}, \mathrm{C}_{2} \mathrm{H}, \mathrm{C}_{2} \mathrm{H}_{3}\right)$ undergoes to functional group elimination, cyclization and ring condensation. It is supposed that the reactions such as ring closure and aromatization are catalysed by the soot surface [13-14].

\section{Results and discussion}

\subsection{Plasma emission spectroscopy}

Several atomic transitions and molecular electronic bands were observed in the plasma spectra. The lines in the range of 700-800 nm are characteristics of Ar atoms (ArI). Other atomic emission lines were identified as hydrogen lines of the Balmer series as alfa, beta lines $\left(\mathrm{H}_{\alpha}=656.28 \mathrm{~nm} ; \mathrm{H}_{\beta}=486.1 \mathrm{~nm}\right)$. The Balmer lines of hydrogen are present in almost all hydrocarbon flames and are extremely bright. The $\mathrm{H}_{\alpha}$ line is the strongest, while the $\mathrm{H}_{\beta}$ line shows broadening, which is attributed to Stark broadening [15]. Oxygen lines (OI) at $777.2 \mathrm{~nm}, 777.4 \mathrm{~nm}$ and $777.5 \mathrm{~nm}$, respectively also appear in the spectra when oxygen is introduced in plasma. Single charged Ar ion lines (ArII) can be found at lower wavelengths of $324.3 \mathrm{~nm}, 349.1 \mathrm{~nm}, 355.9 \mathrm{~nm}$ and $376.5 \mathrm{~nm}$. Carbon atomic (CI) and ion lines (CII, CIII) are not prominent in our spectra in spite of the fact that above $4000 \mathrm{~K}$ carbon atoms and ions occur in great amount in the plasma. Atomic O, C, and $\mathrm{H}$ radicals can initiate further plasma chemical process, and contribute to the formation of radicals and reactive species such as $\mathrm{HO}, \mathrm{HOO}, \mathrm{C}_{2} \mathrm{O}$. A typical emission spectrum of the plasma is shown in Fig. 5.

In the case of hydrocarbon plasmas, only a few molecular species emit in the visible range. One of the most prominent bands in the optical emission spectra was the $\mathrm{C}_{2} \mathrm{Swan}$ 
system $\left(d^{3} \Pi_{g}-a^{3} \Pi_{u}\right)$ with bands between $430 \mathrm{~nm}$ and $650 \mathrm{~nm}$. A rather weak feature of $\mathrm{CH}\left(\mathrm{A}^{2} \Delta-\mathrm{X}^{2} \Pi\right)$ 0-0 band can be found at $431.4 \mathrm{~nm}$. In some of the cases features of a band system could be observed between 380-390 $\mathrm{nm}$. This feature could be assigned as the $\mathrm{B}^{2} \Sigma-\mathrm{X}^{2} \Pi$ transition of $\mathrm{CH}$ radical as a by-product from chlorobenzene decomposition. However, $\mathrm{CH}^{+}$emits also in this area (386-396 nm), which makes the assignation uncertain. In some cases strong features for the $\mathrm{CN}$ violet band $\left(\mathrm{B}^{2} \Sigma^{+}-\mathrm{X}^{2} \Sigma^{+}\right)$ centering at $388 \mathrm{~nm}$ could be observed. The presence of $\mathrm{CN}$ molecular bands in the collected spectra can be explained by the impurity of Ar gas used at high flow rates during the experiments.

The $\mathrm{H}_{2}$ molecule radiates rather weakly throughout the entire visible spectrum having a peak intensity at around $600 \mathrm{~nm}$ in the orange. We observed very weak and noisy, thus rather uncertain sings of the Fulcher band of the $\mathrm{H}_{2}$ molecule between 595-630 nm in our spectra.

One of the important features, which occurred in the spectra with addition of oxygen is the $\mathrm{OH}$ molecular band $(610-650 \mathrm{~nm})$. Fig. 6. depicts a plasma spectrum obtained in presence of oxygen. The two molecular bands are $\mathrm{C}_{2}$ Swan band and the $\mathrm{OH}$ band. The increase of the $\mathrm{O}_{2}$ to $\mathrm{C}_{6} \mathrm{H}_{5} \mathrm{Cl}$ ratio enhanced the $\mathrm{OH}$ and diminished the detection of $\mathrm{CH}$. In some spectra continuous background were seen between 450 and $800 \mathrm{~nm}$. Such broadband emissions were observed in spectra of laser induced graphite plasmas. Emission of $40 \mathrm{~nm}$ diameter particles reaches a maximum at near 550-600 $\mathrm{nm}$ [16]. There are two other sources, which could contribute to the observed continuum, either linear carbon molecules $\left(C_{n}\right.$ with $\left.n \geq 4\right)$ or PAHs.

Previous studies have demonstrated in the plasma laser-induced florescence (LIF) of large gas phase molecules (e.g.: PAHs) can interfere with laser-induce incandescence [17$18]$.

Equilibrium calculations have shown that concentration of linear carbon molecules $\left(\mathrm{C}_{\mathrm{n}}\right.$, $\mathrm{n} \geq 4)$ present in the gas phase in neutral conditions $\left(\mathrm{C}_{6} \mathrm{H}_{5} \mathrm{Cl}+\mathrm{Ar}\right.$ system $)$ is far lower than that of $\mathrm{C}_{2}$ and $\mathrm{C}_{3}$. Additions of oxygen $\left(\mathrm{C}_{6} \mathrm{H}_{5} \mathrm{Cl}+4 \mathrm{O}_{2}+\mathrm{Ar}\right)$ suppress the molar concentration of all the carbon molecules present in the gas phase. Thus the observed continuum in our spectra could be attributed to the interference of the emissions of hot incandescent carbon particles formed in plasma and that of PAHs. 
In accordance with thermodynamic calculations intense soot formation took place under neutral conditions (CLB1, CLB6, CLB8). The soot made difficult to take spectra because of its strong shielding effect.

Optical emission spectra taken at 70 and $180 \mathrm{~mm}$ far from the end of the plasma torch are shown in. Fig. 5. and Fig. 6., respectively. The $\mathrm{C}_{2}$ feature was considerably weaker further from the hot core of the plasma column, while the $\mathrm{CH}$ feature appeared only in the spectrum collected closer to the torch $(70 \mathrm{~mm})$. These radicals $(\mathrm{CH})$ appear through the electron impact dissociative excitation of $\mathrm{C}_{6} \mathrm{H}_{5} \mathrm{Cl}$ molecules.

In oxidative conditions substantial differences were observed in the spectra taken at different distances from the torch in terms of $\mathrm{OH}$ and $\mathrm{H}_{\beta}$ features. The spectrum taken at $70 \mathrm{~mm}$ from the torch contained mainly $\mathrm{OH}$ molecular band, while at $180 \mathrm{~mm}$ strong and broadened $\mathrm{H}_{\beta}$ lines appeared. It suggests that in the high temperature zone chlorobenzene decomposed to its fraction molecules. The $\mathrm{OH}$ radical was formed via reactions between these fractions and oxygen. In cooler parts of the reactor, further from the torch ring closure and condensation of aromatic rings took place.

\subsection{Temperature evaluation from emission spectra}

In the plasma state several physical and chemical processes take place concurrently. Several temperatures (translational, rotational, vibrational, excitation, etc.) can be distinguished. In local thermodynamic equilibrium (LTE) these temperatures are close to each other and consequently close to the electron temperature. Simultaneous determination of these temperatures enables wide characterization of the plasma and the evaluation of the equilibrium phenomena [19].

The excitation temperature $\left(\mathrm{T}_{\mathrm{ex}}\right)$ was determined by the Boltzmann plot according to the following equation:

\section{$\log \left(I_{i j} \lambda_{i j} / g_{i} f_{i j}\right)=-E_{i} / k T_{e x}+C(C:$ constant $)$}

where $\boldsymbol{I}_{i j}$ is the intensity of emission, $\boldsymbol{\lambda}_{i j}$ is the wavelength of each peaks, $\boldsymbol{g}_{i}$ is the statistical weight of upper $\boldsymbol{i}$ energy levels and $\boldsymbol{f}_{\boldsymbol{i}}$ is the oscillator strength. $\boldsymbol{E}_{\boldsymbol{i}}$ is the 
excitation of upper $\boldsymbol{i}$ energy levels and $\boldsymbol{k}$ is the Boltzmann constant.

The excitation temperature was determined using ArI spectral lines observed in the region of 650-1000 nm. These spectral lines were not overlapping with molecular bands. Ten atomic lines for $\mathrm{Ar}$ (at 687.1, 696.5, 703, 714.7, 737.2, 751.4, 794.8, 826.5, 840.8, 842.5 $\mathrm{nm}$ ) were selected for temperature determination. The most intensive ArI lines were neglected from selection due to their higher tendency for self-absorption. Selection of appropriate lines was based on the literature [19-20]. The $\lambda_{i j}, \boldsymbol{g}_{i}, \boldsymbol{f}_{i j}$ and $\boldsymbol{E}_{\boldsymbol{i}}$ values for selected lines were taken from NIST Atomic Spectra Database [21].

Excitation temperature of the pure Ar plasma was found to be 9000-10000 K. This result is in good agreement with data published by others [22]. They have determined the electron temperature of the Ar plasma by the line to continuum method and found it $10000 \mathrm{~K}$. The addition of $\mathrm{O}_{2}$ slightly increased the excitation temperatures to 10000 $12000 \mathrm{~K}$. During chlorobenzene decomposition the excitation temperatures dropped to $7800-8900 \mathrm{~K}$ regardless of the presence of oxygen. The standard deviation uncertainties of the temperature values are $\sim 10 \%$.

To determine $\mathrm{C}_{2}$ Swan temperatures we applied a least-squares fitting program NMT using the Nelder-Mead algorithm, developed at the University of Tennessee Space Institute [23-25]. The method is based on the calculation of positions and intensity of the transitions using an accurate quantum mechanical approach.

For the determination of the $\mathrm{C}_{2}$ Swan temperatures more than 10 spectra were taken in each Run. The error in the vibrational-rotational temperatures reported here were about $\pm 200 \mathrm{~K}$. The standard deviations of the fit of relative intensity were below 0.4 in most cases. The excitation temperatures and the $\mathrm{C}_{2}$ vibration-rotation temperatures under different plasma conditions at $70 \mathrm{~mm}$ from the torch are listed in Table 2. where the $\mathrm{E}_{\text {spec }}$ stands for the energy of RF thermal plasma related to the feed of chlorobenzene $(\mathrm{kWh} \cdot \mathrm{g}$ $\left.{ }^{1}\right)$.

The differences between excitation temperatures (calculated from ArI lines) and Swan temperatures $\left(\mathrm{C}_{2}\right.$ rotational-vibrational bands $)$ imply differences in the spatial distributions of the excitation and relaxation of the particular chemical species [26].

\subsection{Soot particle morphology}


The soot yield was defined as:

\section{$Y_{s}=$ Rate of soot formation $\left(g \cdot h^{-1}\right) /$ Carbon content of the feed-rate of $\mathrm{C}_{6} \mathrm{H}_{5} \mathrm{Cl}\left(\mathrm{g} \cdot \mathrm{h}^{-1}\right)$}

In neutral conditions (CLB1, CLB6, CLB8) high amount of soot was produced as compared to oxidative conditions. Addition of oxygen inhibited soot formation. In oxidative conditions the lowest soot formation was observed in Runs CLB3 and CLB5 and no direct correlation was found between $E_{\text {spec }}$ and $Y_{s}$. The $E_{\text {spec }}$ and the amount of oxygen have combined effect on soot formation.

Fig. 7. shows TEM images of soot obtained after plasma treatment of chlorobenzene in the presence of oxygen (a) and without it (b). Soot was seemingly amorphous and the aggregates had spherical shape with particle size in the $50-150 \mathrm{~nm}$ range. The soot morphology of different Runs was similar.

\subsection{Composition of extract and statistical evaluation of results}

The organic compounds adsorbed on soot were extracted by toluene and the toluene solutions were analyzed by GC/MS, as it was described in the experimental. Beside the fed chlorobenzene numerous organic compounds were identified including polycyclic aromatic hydrocarbons (PAH) such as naphthalene, biphenyl and various isomers of $\mathrm{C}_{12} \mathrm{H}_{8}, \mathrm{C}_{14} \mathrm{H}_{10}, \mathrm{C}_{16} \mathrm{H}_{10}, \mathrm{C}_{18} \mathrm{H}_{10}, \mathrm{C}_{18} \mathrm{H}_{12}$ and $\mathrm{C}_{20} \mathrm{H}_{12} \mathrm{PAH}$ compounds. Chlorinated PAH molecules were also found like chloronaphthalene, chlorobiphenyls, dichlorobiphenyls, $\mathrm{C}_{14} \mathrm{H}_{9} \mathrm{Cl}$ (e.g. chloroantracenes or chlorophenantrenes) and $\mathrm{C}_{16} \mathrm{H}_{9} \mathrm{Cl}$ isomers (e.g. chloropyrenes or chlorofluoranthenes). Figure 8. presents the distribution of PAH compounds of various ring numbers in the toluene extracts. During the decomposition of benzene the highest ring number of PAHs detected in our tests was six $\left(\mathrm{C}_{24} \mathrm{H}_{12}\right)$. In inert condition the whole variety of PAH molecules were formed.

As Fig. 8. presents, higher input power suppressed PAHs formation, especially the formation of higher ring PAHs. This finding is in good agreement with others [27]. It was found that high ring PAHs (5 to 7) did not form easily at high input powers, because the free electrons of higher energy are able to break the rings to shorter fractions most 
probably into $\mathrm{C}_{2} \mathrm{H}_{2}$. Similar trends were observed in oxidative conditions. Fig. 8. shows that the addition of oxygen significantly reduce the amount of both PAHs and chlorinated PAH molecules, too. On the other hand, in oxidative conditions relatively high amount of polychlorinated benzene compounds were formed, while in $\mathrm{C}_{6} \mathrm{H}_{5} \mathrm{Cl}+\mathrm{Ar}$ systems only mono- and dichlorobenzene was detected. Distribution of all the polychlorinated benzene derivatives identified (from chlorobenzene to hexachlorobenzene) in the toluene extracts are illustrated in Fig. 9. Benzyl chloride, ethynyl chlorobenzene, diethynyl chlorobenzene and octachlorocyclopentene $\left(\mathrm{C}_{5} \mathrm{Cl}_{8}\right.$, molecular weight $\left.=344 \mathrm{Da}\right)$ were also detected among the products formed in oxidative conditions.

On the base of conducted tests diagrams were constructed by code Statistica. In these diagrams the amount of the formed compounds is shown related to tests variables such as the oxygen content and the applied power. The diagrams show a definite decrease in the amount of the formed PAH molecules up to $7 \mathrm{wt} \%$ oxygen content, while above that a slight increase occurs. Fig. 10. shows the fitted curve in the case of naphthalene, which was chosen as the simplest of the PAHs.

The amount of chlorinated benzene derivatives rises parallel with the oxygen content. Pentachlorobenzene showed the strongest correlation to the oxygen $\left(\mathrm{R}^{2}=0,936\right)$ on Fig. 11. It seems that in these cases the addition of oxygen is the base of their formation. These results suggest that during the decomposition of chlorobenzene the oxygen content must be around $7 \mathrm{wt} \%$ to keep the formation of chlorine containing benzene derivatives and PAH molecules at minimum. The effect of power and feed rate seems negligible beside oxygen.

\section{Conclusions}

In this study chlorobenzene was used as a model compound to reveal the decomposition processes of halogenated aromatic hydrocarbons in RF thermal plasma reactor. We employed optical emission spectroscopy to identify the numerous species in the plasma. Besides the atomic lines of $\mathrm{H}, \mathrm{O}$ and $\mathrm{C}$, various radicals, such as $\mathrm{OH}, \mathrm{C}_{2}$ and $\mathrm{CH}$ were detected. The presence and the amount of these radicals depend on the temperature of the observed region of the plasma column. In higher temperature region $(\mathrm{T}>9000 \mathrm{~K})$ 
formation of $\mathrm{C}_{2}, \mathrm{OH}$ and $\mathrm{CH}$ are favoured, while in the lower one ( $\left.\mathrm{T}>7800 \mathrm{~K}\right)$ presence of $\mathrm{H}$ is higher. The excitation temperature was calculated as $9000-10000 \mathrm{~K}$, while the $\mathrm{C}_{2}$ Swan temperature was 4000-4500 K.

The particle size of the formed soot ranges from 50 to $150 \mathrm{~nm}$. Compounds adsorbed on the surface of the soot comprise various PAH and chlorinated PAH molecules as well as polychlorinated benzene derivatives in much smaller amount. Both the applied power of the plasma and the oxygen concentration has a great effect on the amount of the formed PAH molecules. The higher input power reduces the ring number of the molecules. In the presence of oxygen their amount decreased and had a minimum at $7 \%$ but higher oxygen content their formation enhanced. The amount of chlorinated benzene derivatives increased parallel with increasing oxygen content.

\section{Acknowledgements}

The authors kindly acknowledge the financial support of the National Office for Research and Technology (REG-KM-09-1-2009-0005 and TÁMOP-4.2.2/B-10/1-2010-0025). 


\section{References}

1. Feltens R, Mögel I, Röder-Stolinski C, Simon JC, Herberth G, Lehmann I (2010) Chlorobenzene induces oxidative stress in human lung epithelial cell in vitro. Toxicol Appl Pharm 242:100-108

2. Kusters E, Lauwerys R (1990) Biological monitoring of exposure to monochlorobenzene. Int Arch Occup Environ Health 62:329-331

3. Howard PH (1989) Handbook of Environmental Fate and Exposure Data for Organic Chemicals, Vol. 1: Large Production and Priority Pollutants. Lewis Publishers, Chelsea, UK

4. Meharg AA, Wright J, Osbornl D (2000) Chlorobenzenes in rivers draining industrial catchments. 251-252:243-253

5. Roex EWM, Giovannangelo M, van Gestel CAM (2001) Reproductive impairment in the zebrafish, Danio rerio, upon chronic exposure to 1,2,3-trichlorobenzene. Ecotox Environ Safe 48:196-201

6. Qian Y, Yin D, Li Y, Wang J, Zhang M, Hu S (2004) Effects of four chlorobenzenes on serum sex steroids and hepatic microsome enzyme activities in crucian carp, Carassius auratus. Chemosphere 57:127-133

7. Fadli A, Briois C, Baillet C, Sawerysyn JP (1999) Experimental study on the thermal oxidation of chlorobenzene at $575-825^{\circ} \mathrm{C}$. Chemosphere $38: 2835-2848$

8. Mohai I, Gál L, Szépvölgyi J, Gubicza J, Farkas Z (2007) Synthesis of nanosized zinc ferrites from liquid precursors in RF thermal plasma reactor. $\mathrm{J}$ Eur Ceram Soc 27:941-945

9. Nemes L, Irle S (2009) Spectroscopy, dynamics and molecular theory of carbon plasmas and vapors. World Scientific Publishing, Abingdon, UK

10. Al-Shboul KF, Harilal SS, Hassanein A, Polek M (2011) Dynamics of $\mathrm{C}_{2}$ formation in laser-produced carbon plasma in helium environment. J App Phys 109:053302

11. Nemes L, Keszler AM, Hornkohl JO, Parigger CG (2005) Laser-induced carbon plasma emission spectroscopic measurements on solid targets and in gas-phase optical breakdown. Appl Opt 44:3661-3667

12. Cota-Sanchez G, Soucy G, Huczko A, Lange H (2005) Induction plasma synthesis of fullerenes and nanotubes using carbon black-nickel particles. Carbon 43:3153-3166 
13. Föglein KA, Szépvölgyi J, Szabó PT, Mészáros E, Pekker-Jakab E, Babievskaya IZ, Mohai I, Károly Z (2005) Comparative study on decomposition of $\mathrm{CFCl} 3$ in thermal and cold plasma. Plasma Chem Plasma Proc 25:275-288

14. Richter H, Howard JB (2000) Formation of polycyclic aromatic hydrocarbons and their growth to soot - a review of chemical reaction pathways. Prog Energ Combust 26:565-608

15. Parigger CG, Plemmons DH, Oks E (2003) Balmer series H $\beta$ measurements in a laser-induced hydrogen plasma. Appl Opt 42:5992-6000

16. Nemes L, Keszler AM, Parigger CG, Hornkohl JO, Michelsen HA, Stakhursky V (2007) Spontaneous emission from the $\mathrm{C}_{3}$ radical in carbon plasma. Appl Opt 46:4032-4040

17. Smyth KC, Shaddix CR, Everest DA (1997) Aspects of soot dynamics as revealed by measurements of broadband fluorescence and flame luminosity in flickering diffusion flames. Combust Flame 111:185-194

18. Goulay F, Schrader PE, Nemes L, Dansson MA, Michelsen HA (2009) Photochemical interferences for laser-induced incandescence of flame-generated soot. Proc Combust Inst 32:963-970

19. Jamroz P, Zyrnicki W (2010) Optical emission spectroscopy study for nitrogenacetylene-argon and nitrogen-acetylene-helium $100 \mathrm{kHz}$ and DC discharges. Vacuum 84:940-946

20. Yugeswaran S, Selvarajan V (2006) Electron number density measurements on a DC argon plasma jet by stark broadening of Ar I spectral line. Vacuum 81:347-352

21. NIST atomic spectra database, http://physics.nist.gov/PhysRefData/ASD/index.html

22. Bastiaans GJ, Mangold RA (1985) The calculation of electron density and temperature in $\mathrm{Ar}$ spectroscopic plasma from continuum and line spectra. Spectrochim Acta Part B 40:885-892

23. Hornkohl JO, Parigger CG, Lewis JWL (1991) Temperature measurements from CN spectra in a laser-induced plasma. J Quant Spectrosc Radiat Transfer 46:405-411

24. Parigger CG, Plemmons DH, Hornkohl JO, Lewis JWL (1994) Spectroscopic temperature measurements in a decaying laser-induced plasma using the $\mathrm{C}_{2}$ Swan system. J Quant Spectrosc Radiat Transfer 52:707-711 
25. Parigger CG, Hornkohl JO, Keszler AM, Nemes L (2003) Measurements and analysis of atomic and diatomic carbon spectra from laser ablation of graphite. Appl Opt 42:6192-6198

26. Okada A, Kijima K (2002) Analysis of optical emission spectra from ICP of Ar-SiH4$\mathrm{CH}_{4}$ system. Vacuum 65:319-326

27. Shih SI, Lin TC, Shih M (2005) Decomposition of benzene in the RF plasma environment: Part II. Formation of polycyclic aromatic hydrocarbons. J Hazard Mater 117:149-159 
Tables

Table 1. Tests conditions

\begin{tabular}{cccc}
\hline Run & Plate power $(\mathbf{k W})$ & Feed rate $\left(\mathbf{g} \cdot \mathbf{h}^{-\mathbf{1}}\right)$ & $\begin{array}{c}\text { Oxygen content } \\
(\text { volume\%) }\end{array}$ \\
\hline CLB 1 & 15 & 150 & 0 \\
CLB 2 & 15 & 250 & 10 \\
CLB 3 & 15 & 350 & 5 \\
CLB 4 & 20 & 150 & 10 \\
CLB 5 & 20 & 250 & 5 \\
CLB 6 & 20 & 350 & 0 \\
CLB 7 & 25 & 150 & 5 \\
CLB 8 & 25 & 250 & 0 \\
CLB 9 & 25 & 350 & 10 \\
\hline
\end{tabular}


Table 2. Plasma temperatures and soot yields

\begin{tabular}{ccccc}
\hline Run & $\mathbf{E}_{\text {spec }}$ & $\mathbf{C}_{\mathbf{2}}$ Swan temp. (K) & $\begin{array}{c}\mathbf{T}_{\mathbf{g}} \text { Excit. Temp } \\
(\mathbf{K})\end{array}$ & $\begin{array}{c}\mathbf{Y}_{\mathbf{S}} \\
\mathbf{( \% )}\end{array}$ \\
\hline CLB 1 & 0.10 & 4200 & 7800 & 35.78 \\
CLB 2 & 0.05 & - & 8900 & 3.91 \\
CLB 3 & 0.06 & 4300 & 12000 & 1.41 \\
CLB 4 & 0.11 & 4000 & - & 4.22 \\
CLB 5 & 0.08 & 4100 & 7800 & 1.25 \\
CLB 6 & 0.05 & 5500 & 7800 & 8.75 \\
CLB 7 & 0.13 & 3900 & 8900 & 5.47 \\
CLB 8 & 0.09 & 4300 & 8900 & 25.00 \\
CLB 9 & 0.06 & 4400 & 10400 & 2.34 \\
\hline
\end{tabular}




\section{List of Figure Captions}

Fig. 1. Schematic representation of the reactor

Fig. 2. Graphical representation of the experimental conditions

Fig. 3. Thermodynamic calculation for the $\mathrm{C}_{6} \mathrm{H}_{5} \mathrm{Cl}+\mathrm{Ar}$ system

Fig. 4. Thermodynamic calculation for the $\mathrm{C}_{6} \mathrm{H}_{5} \mathrm{Cl}+14 \mathrm{O}_{2}+\mathrm{Ar}$ system

Fig. 5. Emission spectrum of plasma during chlorobenzene decomposition in oxygen environment (CLB4) at $7 \mathrm{~cm}$ from the torch

Fig. 6. Emission spectrum of RF chlorobenzene plasma in presence of oxygen in the 350$800 \mathrm{~nm}$ range (CLB3) recorded at $18 \mathrm{~cm}$ from the torch

Fig. 7a. TEM micrographs of solid product sample from the CLB4 experiment

Fig. 7b. TEM micrographs of solid product sample from the CLB6 experiment

Fig. 8. Distribution of various ring numbers decomposition of chlorobenzene

Fig. 9. Distribution of various chlorinated compounds in neutral and oxidative conditions

Fig. 10. Fitted curve in the case of naphthalene

Fig. 11. Fitter curve in the case of pentachlorobenzene 
Figures

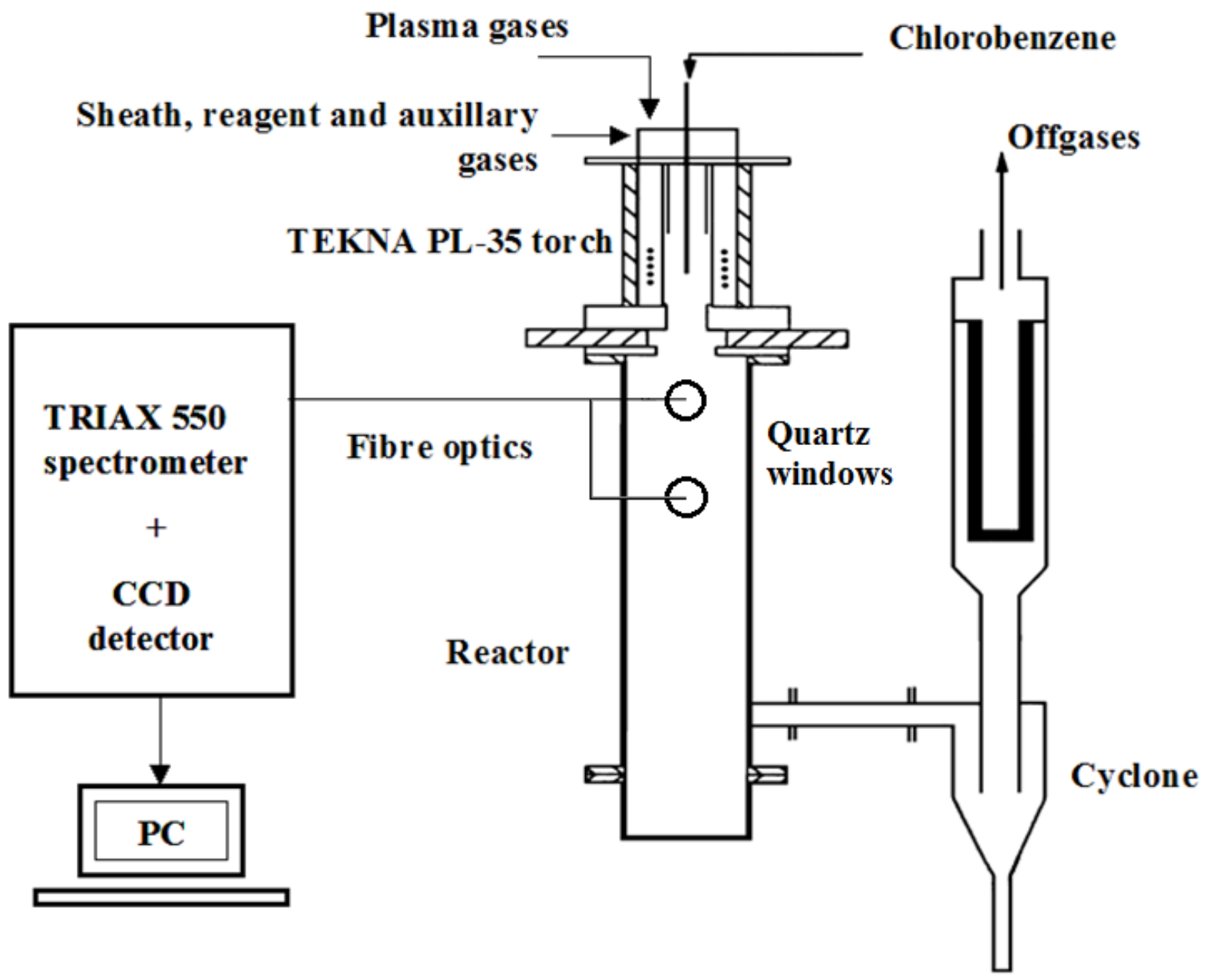

Fig. 1. Schematic representation of the reactor 


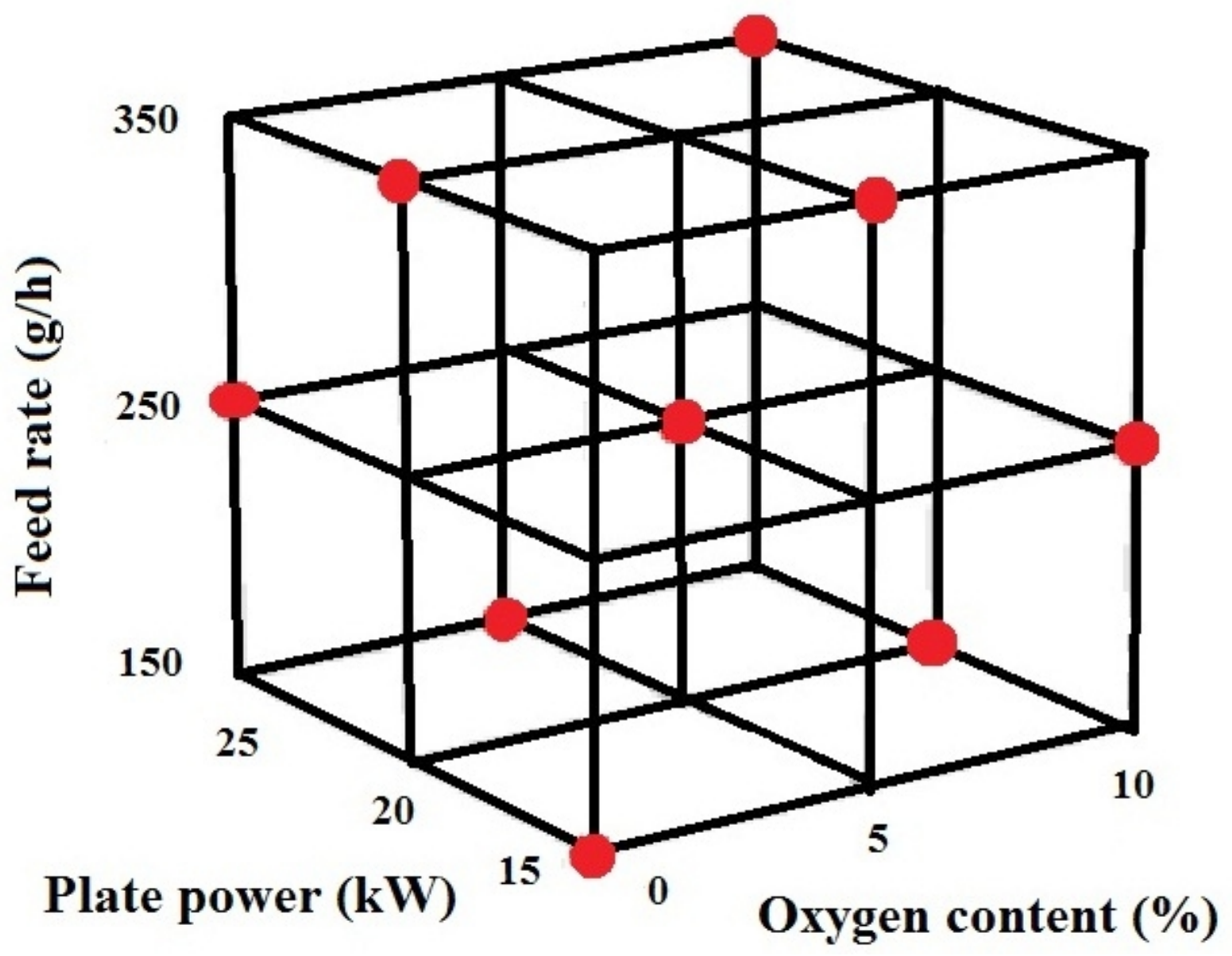

Fig. 2. Graphical representation of the experimental conditions 


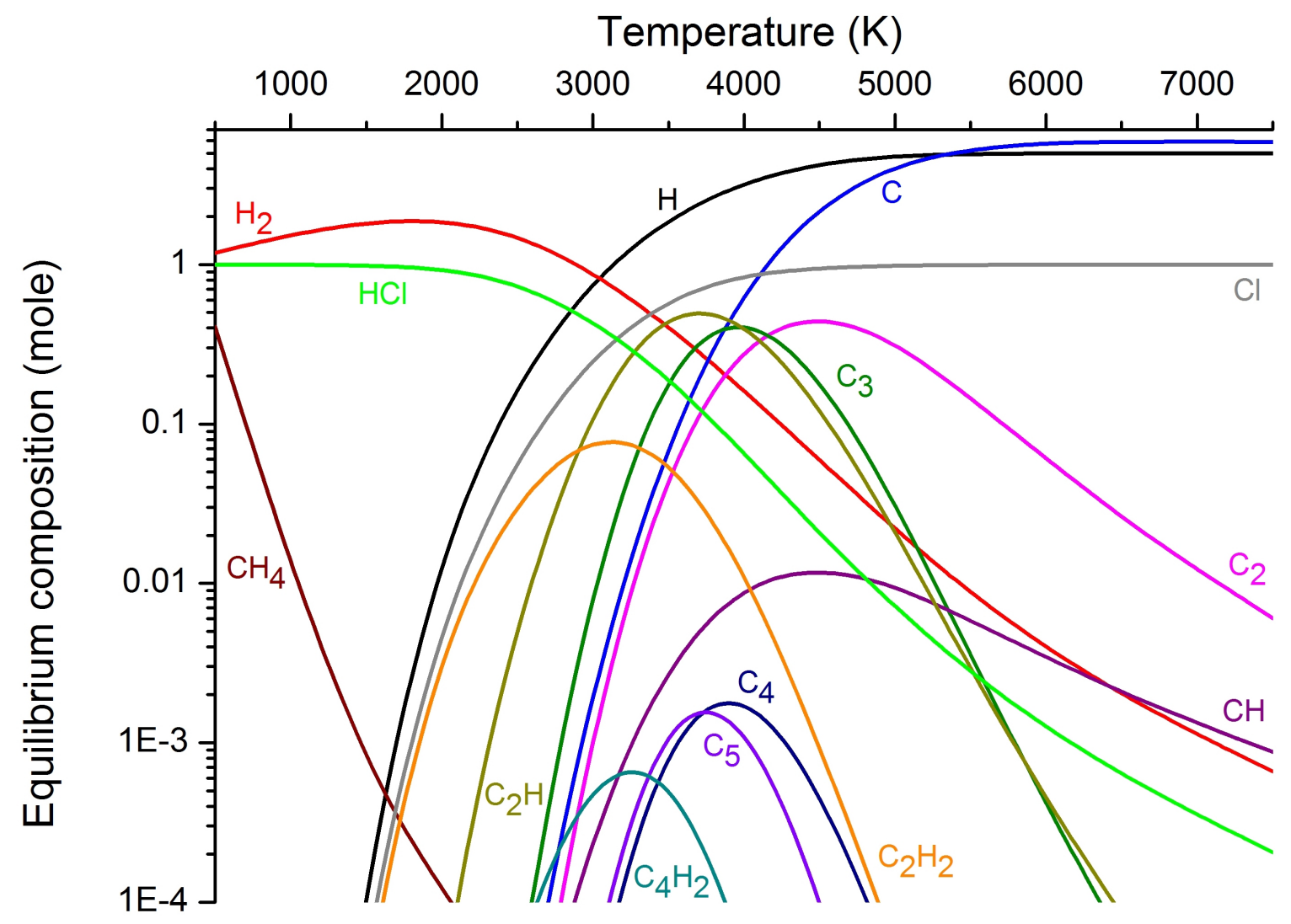

Fig. 3. Thermodynamic calculation for the $\mathrm{C}_{6} \mathrm{H}_{5} \mathrm{Cl}+\mathrm{Ar}$ system 


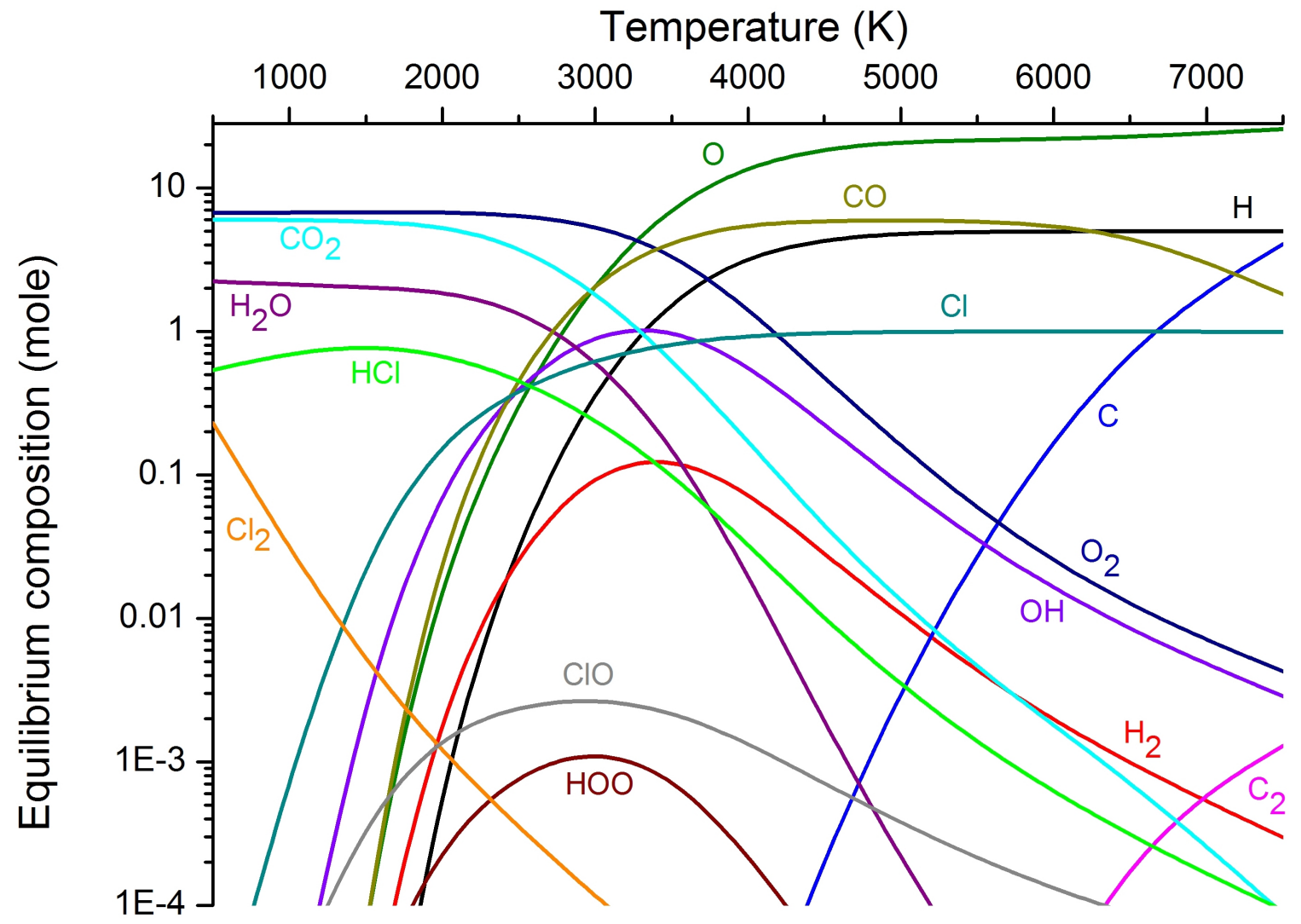

Fig. 4. Thermodynamic calculation for the $\mathrm{C}_{6} \mathrm{H}_{5} \mathrm{Cl}+14 \mathrm{O}_{2}+\mathrm{Ar}$ system 


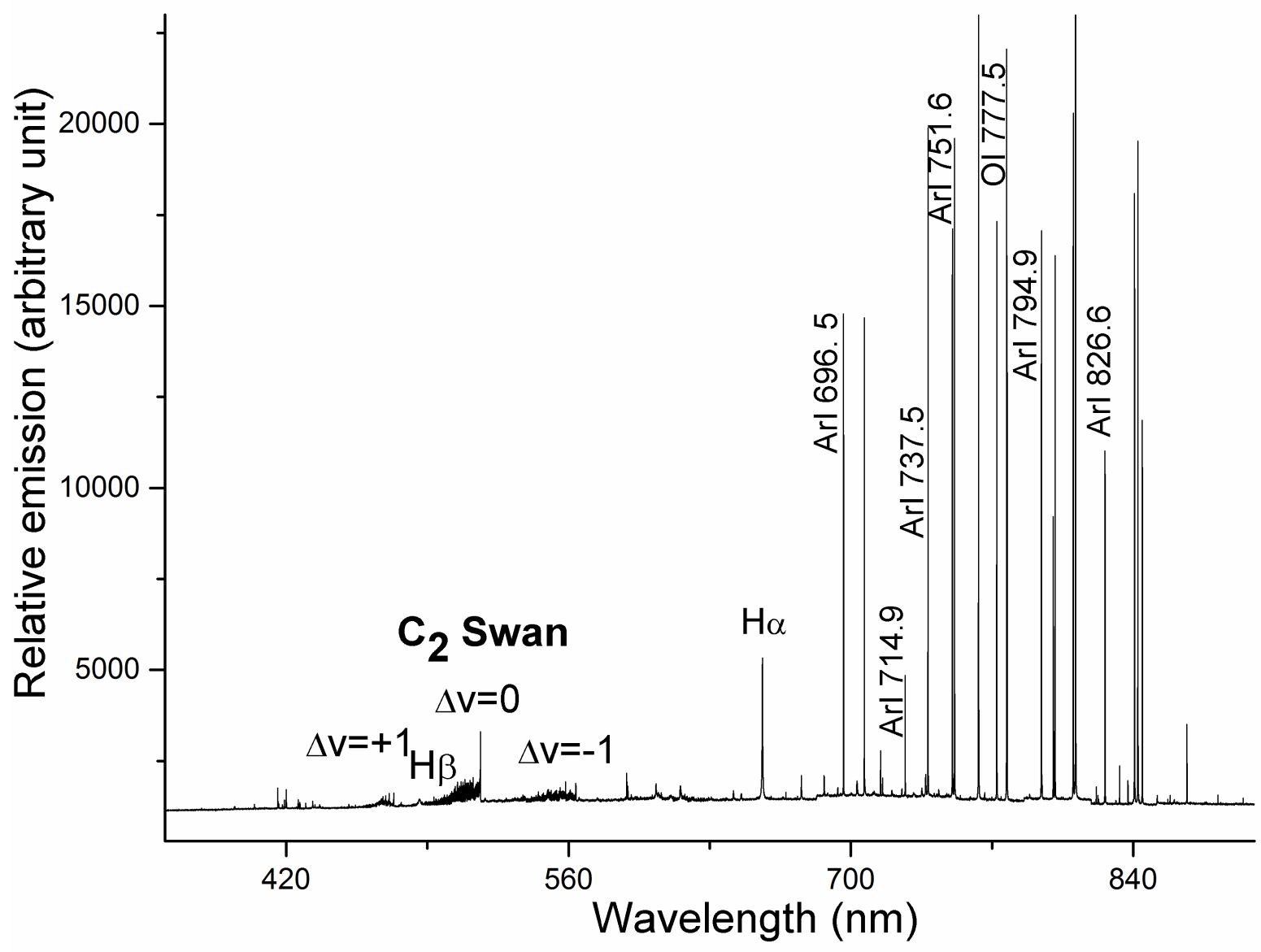

Fig. 5. Emission spectrum of plasma during chlorobenzene decomposition in oxygen environment (CLB4) at $7 \mathrm{~cm}$ from the torch 


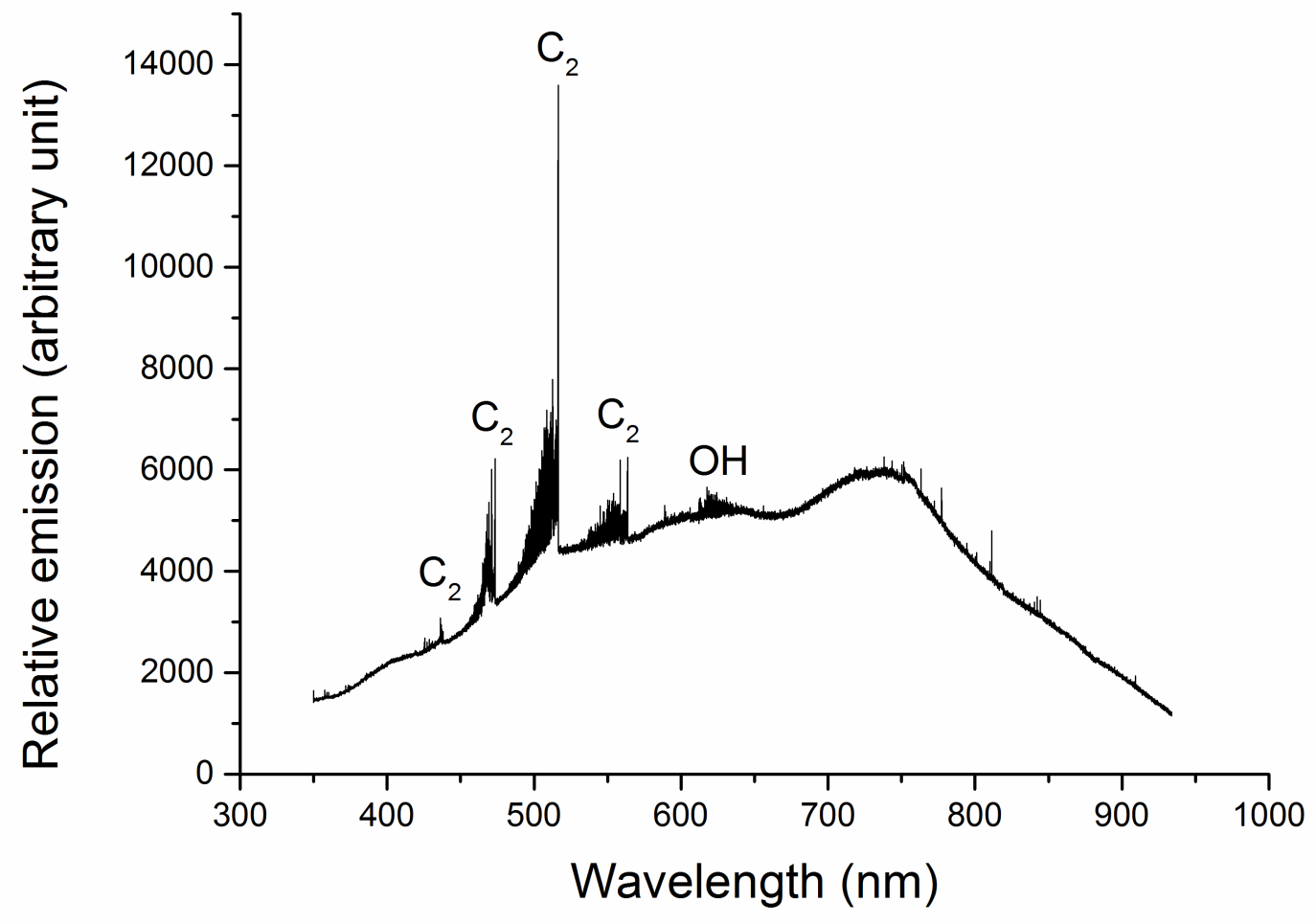

Fig. 6. Emission spectrum of RF chlorobenzene plasma in presence of oxygen in the 350$800 \mathrm{~nm}$ range (CLB3) recorded at $18 \mathrm{~cm}$ from the torch 


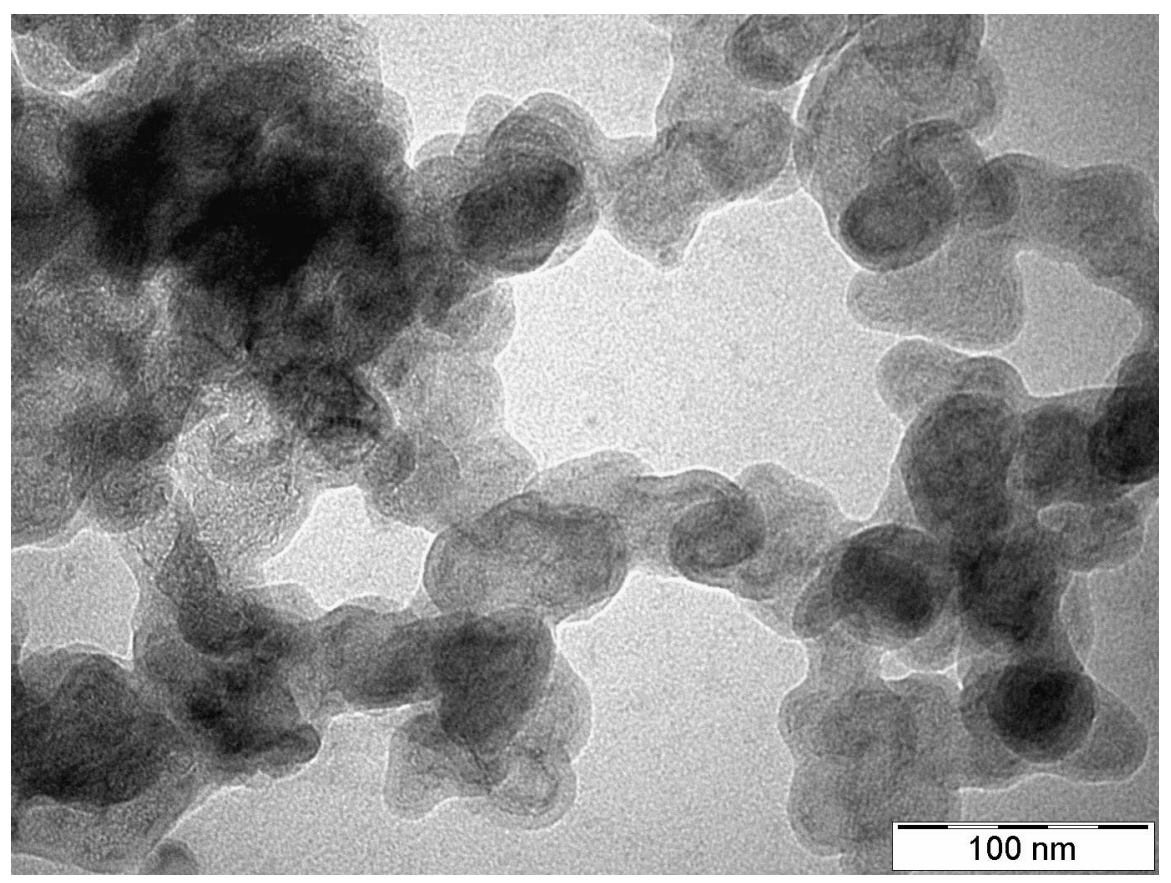

Fig. 7a. TEM micrographs of solid product sample from the CLB4 experiment

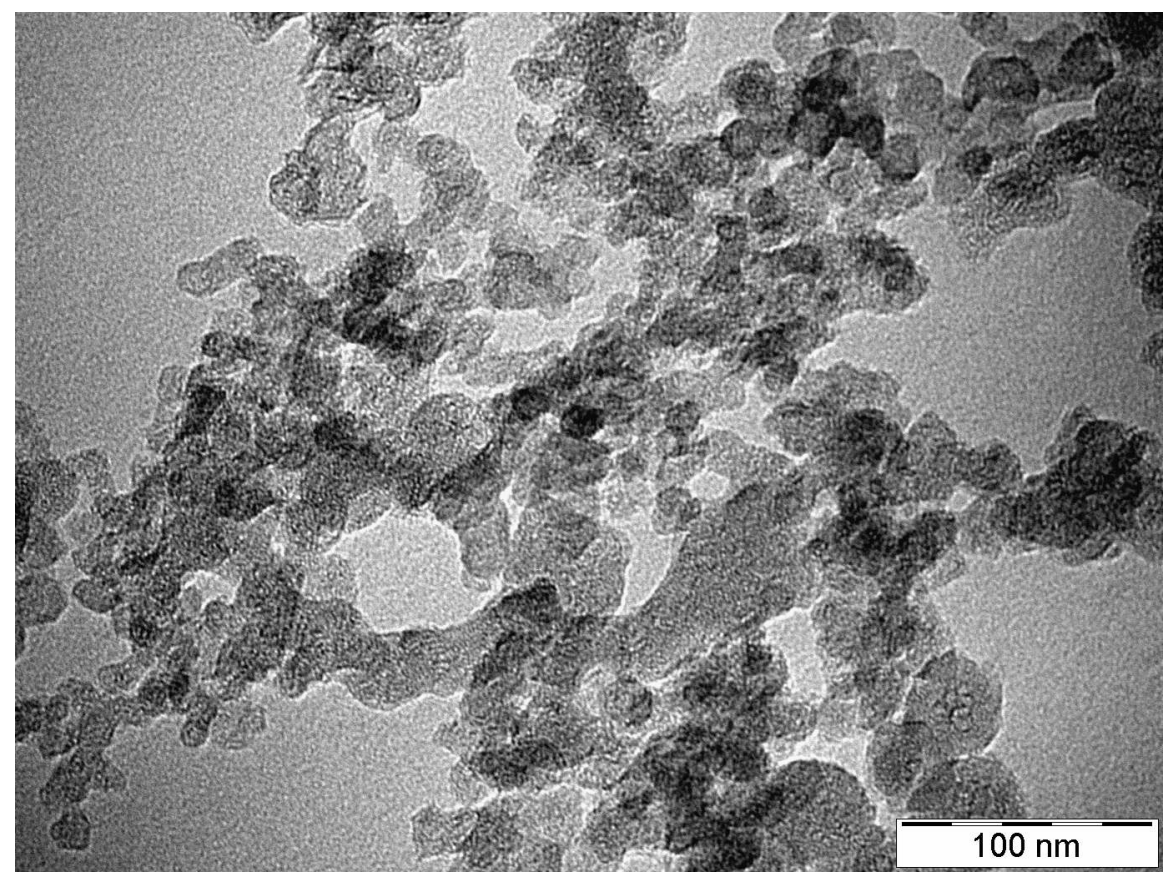

Fig. 7b. TEM micrographs of solid product sample from the CLB6 experiment 


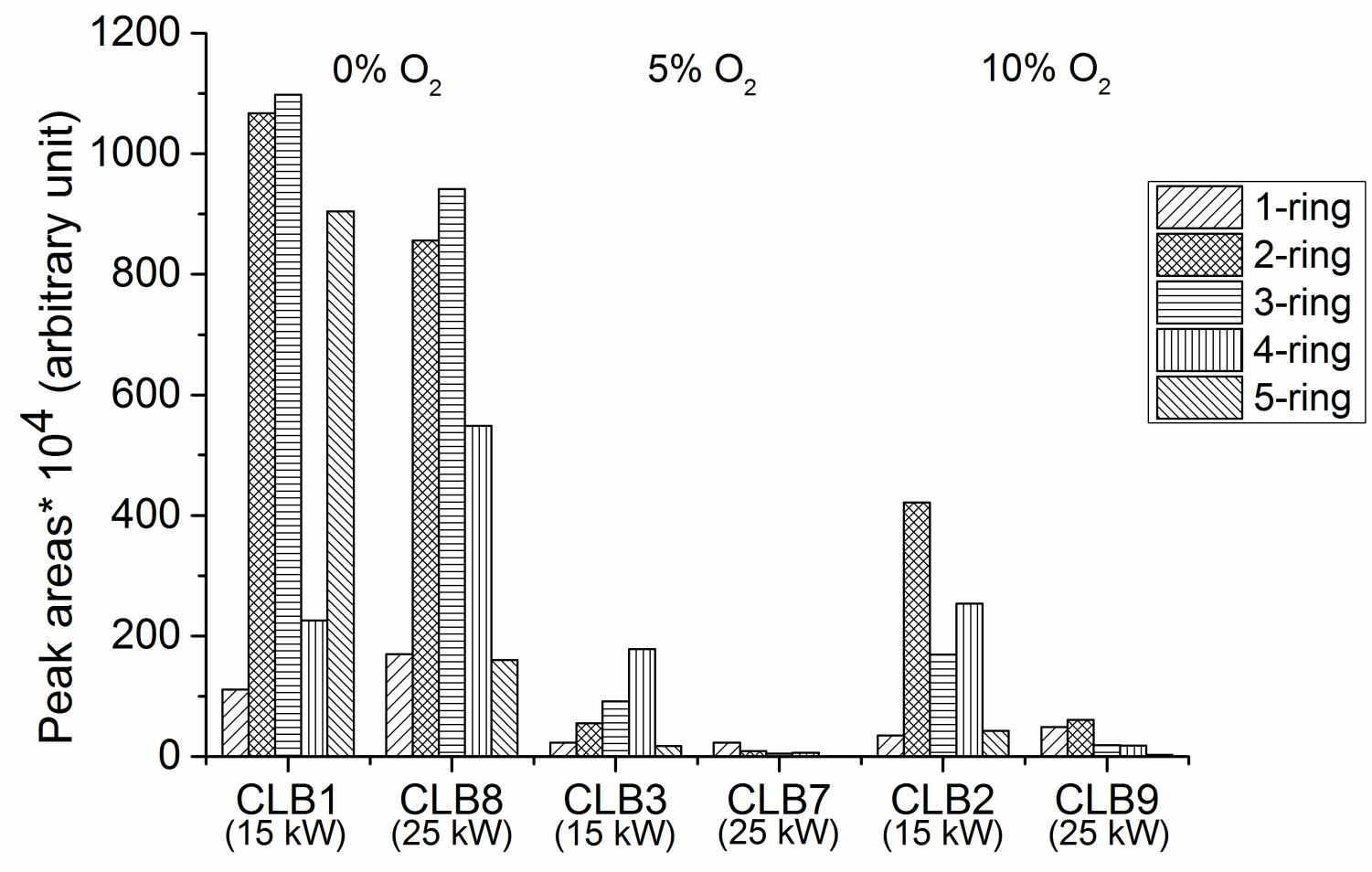

Fig. 8. Distribution of various ring numbers decomposition of chlorobenzene 


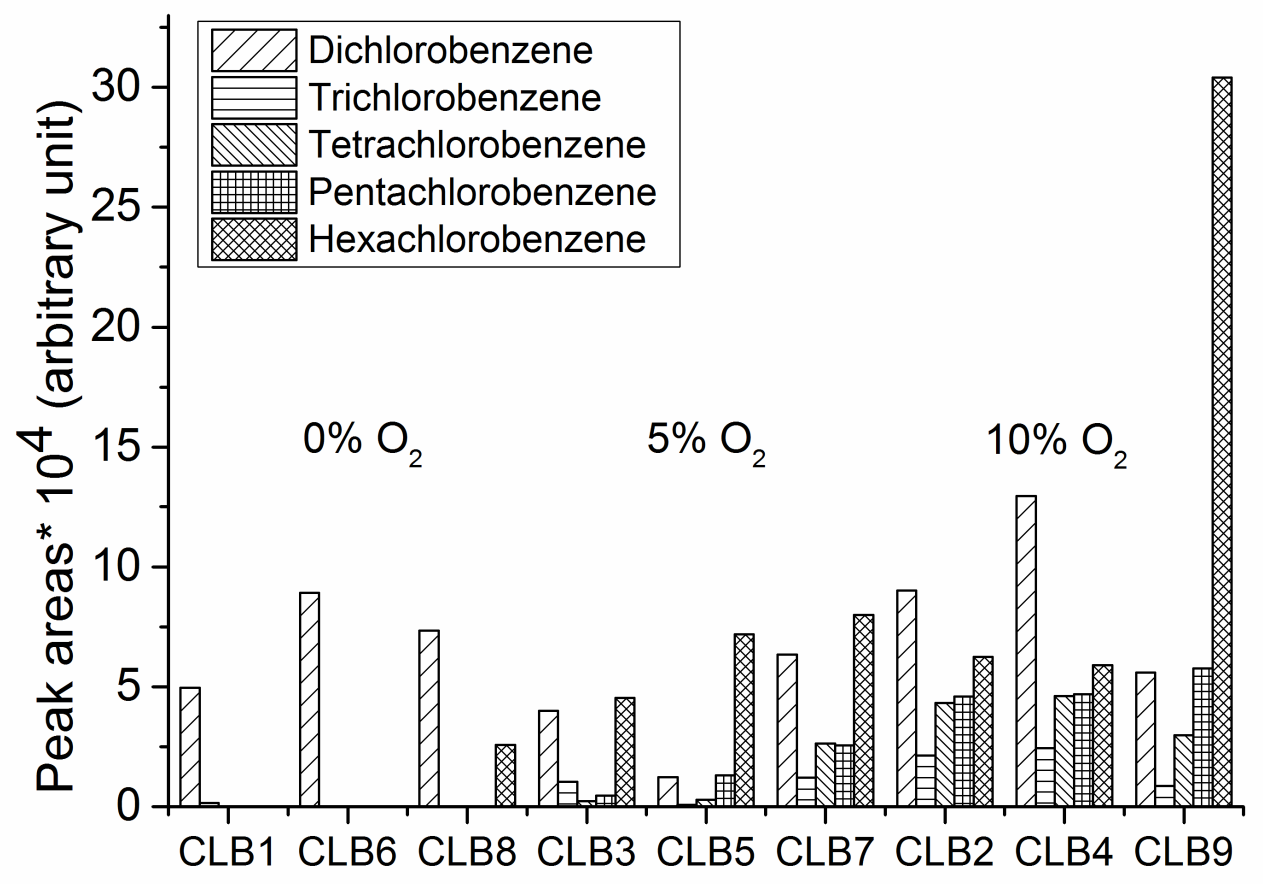

Fig. 9. Distribution of various chlorinated compounds in neutral and oxidative conditions 


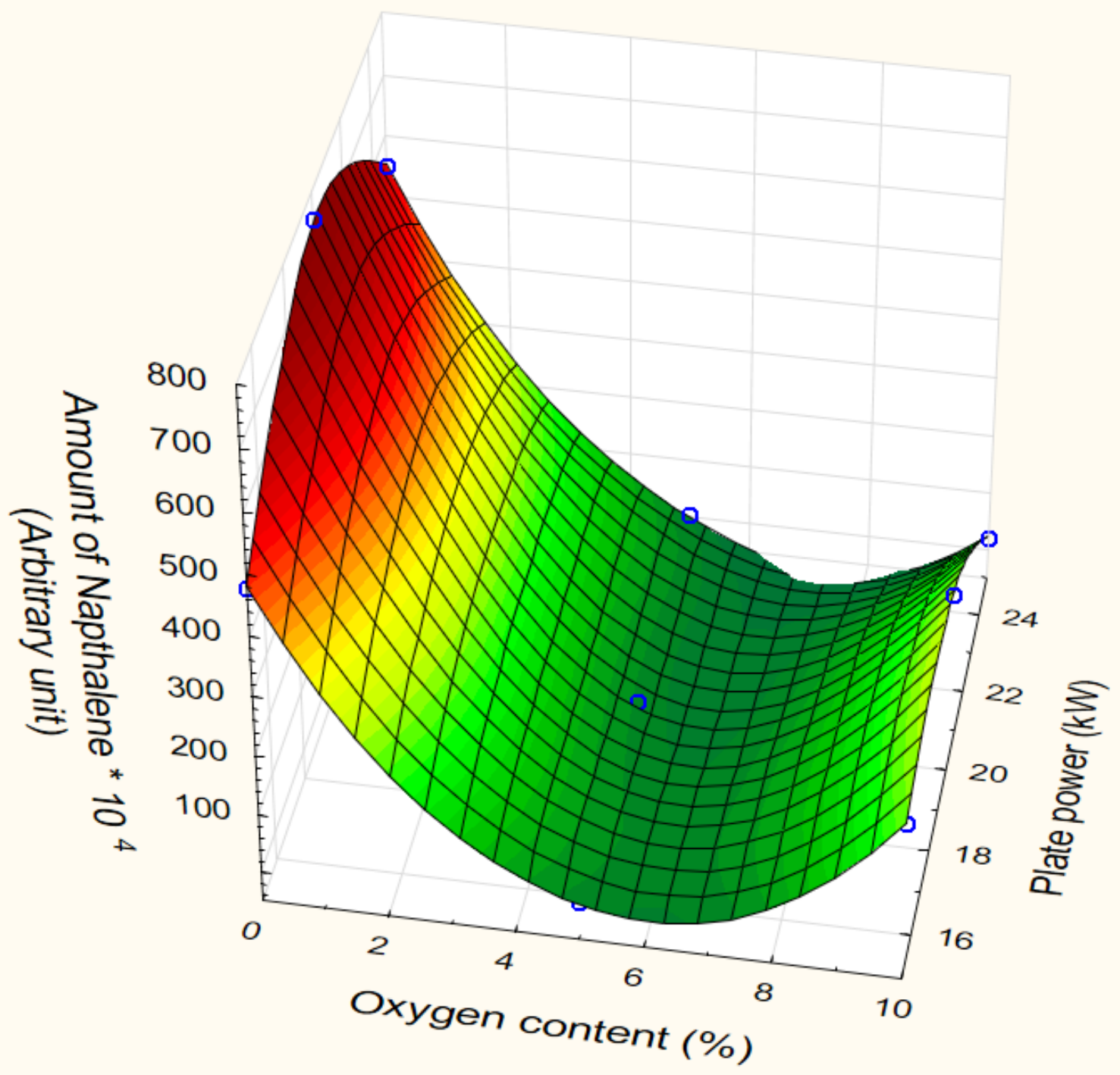

Fig. 10. Fitted curve in the case of naphthalene 


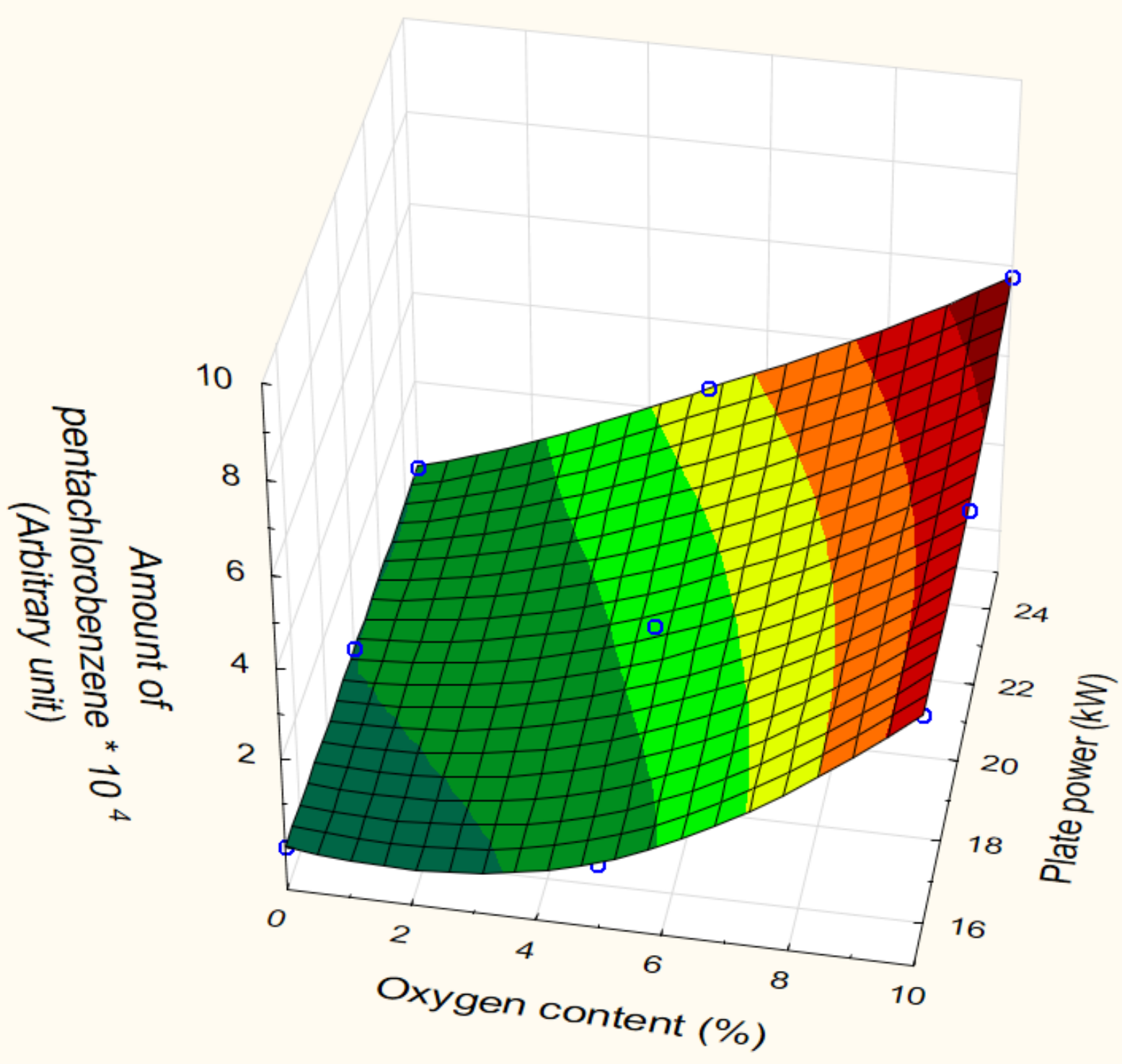

Fig. 11. Fitter curve in the case of pentachlorobenzene 